\title{
Interpretasi Anomali Data Gravitasi Daerah Panas Bumi "K51S" Berdasarkan Pemodelan 3D
}

\author{
Anis Hoerunisa ${ }^{*}$ and Sismanto
}

Received: June 10, 2020 | Accepted: Aug. 05, 2020 | Published: Dec. 21, 2020 | DOI: 10.22146/jfi.v24i3.56789

\section{Ringkasan}

Daerah panas bumi "K51S" merupakan salah satu daerah yang memiliki potensi panas bumi di daerah Sulawesi Tengah. Potensi panas bumi tersebut ditandai dengan adanya manifestasi berupa air panas. Studi lebih lanjut dilakukan untuk mengetahui keberadaan struktur bawah permukaan daerah panas bumi. Salah satu metode yang dapat digunakan dalam eksplorasi panas bumi adalah metode gravitasi. Metode gravitasi merupakan metode geofisika untuk memetakan nilai medan gravitasi bawah permukaan secara lateral. Penelitian ini bertujuan untuk mengetahui pola sebaran anomali residual dan batas kedalaman heat source dan reservoir daerah penelitian, serta memperoleh gambaran struktur geologi bawah permukaan sistem panas bumi daerah penelitian. Data penelitian yang digunakan adalah data sekunder hasil survei lapangan Tim Geofisika Pusat Sumber Daya Mineral Batubara dan Panas bumi (PSDMBP) berupa data anomali gravitasi observasi. Data tersebut kemudian dilakukan pengolahan hingga diperoleh data anomali bouger lengkap $(A B L)$, reduksi bidang datar, dan kontinuasi ke atas untuk pemisahan anomali regional dan residual.

Hasil anomali residual menunjukan nilai anomali tinggi pada rentang $5-13 \mathrm{mGal}$ yang bersesuaian dengan batuan vulkanik dan anomali rendah berada pada rentang $-10-4 \mathrm{mGal}$ tersebar merata di antara anomali tinggi daerah penelitian. Interpretasi pemodelan 3 dimensi menunjukan adanya struktur yang mengontrol sistem panas bumi daerah penelitian adalah sesar Koalarawa dan Towingkoloe. Batuan penyusun sistem panas bumi "K51S" yaitu batuan heat source diinterpretasikan sebagai granit dengan densitas $2,64-3,30 \mathrm{gr} / \mathrm{cm}^{3}$ pada kedalaman lebih dari $6 \mathrm{~km}$, batuan reservoir diinterpretasikan sebagai batupasir dengan densitas $1,20-2,34 \mathrm{gr} / \mathrm{cm}^{3} \mathrm{pada}$ kedalaman $1,3 \mathrm{~km}$, batuan caprock diinterpretasikan sebagai batupasir dengan densitas $2,35-2,63 \mathrm{gr} / \mathrm{cm}^{3}$ pada kedalaman $0,8 \mathrm{~km}$, densitas $2,64-3,30 \mathrm{gr} / \mathrm{cm}^{3}$ diinterpretasikan sebagai batuan vulkanik, dan endapan permukaan diinterpretasikan sebagai alluvial.

Kata Kunci : data gravitasi, pemodelan 3D, heat source, reservoir.

\section{Abstract}

"K51S" geothermal field is one area of geothermal potential area in Central Sulawesi. The geothermal potential is usually characterized by the manifestation of hot spring. Further studies are conducted to determine the existence of subsurface structures in geothermal areas. One method that can be used in geothermal exploration is the gravity method. The gravity method is a geophysical method to map lateral subsurface gravity fields. This study aims to obtain an overview of subsurface structures, determine the existence of heat sources and reservoirs based on the results of interpretations of 3D modeling. The research data used are secondary data from the field survey of the Geophysics Team of the Coal Mineral and Geothermal Resource Center (PSDMBP) in the form of observational gravity anomaly data. The data is then processed until complete Bouger anomaly $(A B L)$ data is obtained, flat surface reduction, and upward continuation for the separation of regional and residual anomalies.

The results of residual anomalies show high anomaly values in the range of $5-13 \mathrm{mGal}$ corresponding to volcanic rocks and low anomalies in the range of $-10-4 \mathrm{mGal}$ spread evenly between high anomalies in the study area. The interpretation of 3-dimensional modeling shows the structure that controls the geothermal system in the study area is the Koalarawa and Towingkoloe faults. The rocks making up the "K51S" geothermal system namely: heat source rocks interpreted as granite with a density of 2,64-3,30 gr $/ \mathrm{cm}^{3}$ at a depth of more than 6 $\mathrm{km}$, reservoir rocks interpreted as sandstones with a density of $1,20-2,34 \mathrm{gr} / \mathrm{cm}^{3}$ at depth of $1.3 \mathrm{~km}$, caprock are interpreted as a sandstone with a density of $2,35-2,63 \mathrm{gr} / \mathrm{cm}^{3}$ at a depth of $0,8 \mathrm{~km}$, the density of 2,64$3,30 \mathrm{gr} / \mathrm{cm}^{3}$ interpreted as volcanic rocks, and surface deposited in the form of alluvial.

Keywords: gravity data; 3D modeling; heat source; reservoir. 


\section{PENDAHULUAN}

Indonesia adalah wilayah dengan keadaan tektonik yang cukup kompleks, hal ini diketahui bahwa Indonesia terletak pada pertemuan antara tiga lempeng tektonik, yaitu lempeng Indo-Australia, lempeng Eurasia, dan lempeng Pasifik [1]. Adanya pertemuan lempeng tektonik menyebabkan terbentuknya pegunungan dengan karakteristik dan tipe yang berbeda. Pegunungan aktif dapat menghasilkan sumber energi panas bumi, dengan begitu Indonesia memiliki potensi panas bumi yang cukup besar. Potensi energi panas bumi di Indonesia adalah 28.617 MWe, hal ini setara dengan $40 \%$ cadangan panas bumi yang ada di dunia. Energi panas bumi tersebut tersebar di 30 provinsi yaitu pulau Sumatera, Jawa, Nusa Tenggara, Maluku, dan Sulawesi [2].

"K51S" merupakan salah satu daerah di Sulawesi Tengah yang memiliki manifestasi permukaan, berupa air panas. Manifestasi tersebut merupakan salah satu indikasi adanya sistem panas bumi di daerah penelitian. Manifestasi air panas tersebut dikontrol oleh beberapa sesar yang ada di daerah penelitian. Morfologi daerah penelitian tersusun atas satuan geomorfologi perbukitan terjal, pedataran dan perbukitan bergelombang. Daerah penelitian tersusun atas batuan alluvial, batupasir, granit, dan batuan vulkanik. Hasil penelitian sebelumnya terkait dengan sistem panas bumi di daerah penelitian di peroleh bahwa:

1 Penelitian dengan menggunakan metode magnetotelurik (MT) dan Time Domain Electro Magnetic (TDEM), hasil menunjukan lapisan penudung (caprock) berada pada kedalaman 0-500 m, dan reservoir pada kedalaman 500-700 m. [3]

2 Penelitian dengan menggunakan metode Audio Magnetotelluric (AMT) dengan pemodelan 2D, hasil menunjukan terdapat caprock pada kedalaman 0 - $1000 \mathrm{~m}$, dan reservoir pada kedalaman 750 - $1000 \mathrm{~m}$. [4]

Metode gravitasi adalah salah satu metode geofiska untuk mengetahui sebaran densitas struktur bawah permukaan. Metode gravitasi dapat memberikan informasi yang cukup detail terkait dengan struktur bawah permukaan melalui kontras densitas batuan, sehingga keberadaan sumber panas di bawah permukaan bumi dapat diketahui. Panas di dalam permukaan dapat mempengaruhi karakteristik dari batuan yang berada di tempat tersebut, berubahnya

\footnotetext{
${ }^{*}$ Correspondence: hoerunisaanis@gmail.com

Departemen Fisika, Fakultas Matematika dan Ilmu Pengetahuan , Universitas Gadjah Mada, Yogyakarta, Indonesia

Full list of author information is available at the end of the article

${ }^{\dagger}$ Equal contributor
}

karakteristik batuan menyebabkan berubahnya nilai densitas bawah permukaan yang menjadikan nilai gravitasi observasi terukur di permukaan juga berbeda [5]. Pemodelan tiga dimensi dilakukan untuk mengetahui struktur bawah permukaan berupa batuan dasar dari sistem panas bumi daerah penelitian secara lebih nyata dan realistis. Sehingga dilakukan pemodelan tiga dimensi berdasarkan data anomali gravitasi daerah panas bumi "K51S" untuk mengetahui gambaran geologi bawah permukaan dan batas kedalaman sumber panas (heat source) dan reservoir serta hasil analisis anomali data gravitasi.

\section{METODE PENELITIAN}

Penelitian ini dilakukan di Departemen Fisika yang bertempat di Gedung S2/S3 MIPA, Jurusan Fisika, Fakultas MIPA, Universitas Gadjah Mada. Daerah yang menjadi target penelitian adalah lapangan panas bumi "K51S" tepatnya berada di Provinsi Sulawesi Tengah. Luas area penelitian sesuai dengan peta daerah penelitian adalah $22,5 \mathrm{~km} \times 25 \mathrm{~km}$. Peta daerah penelitian dapat dilihat pada Gambar 1 .

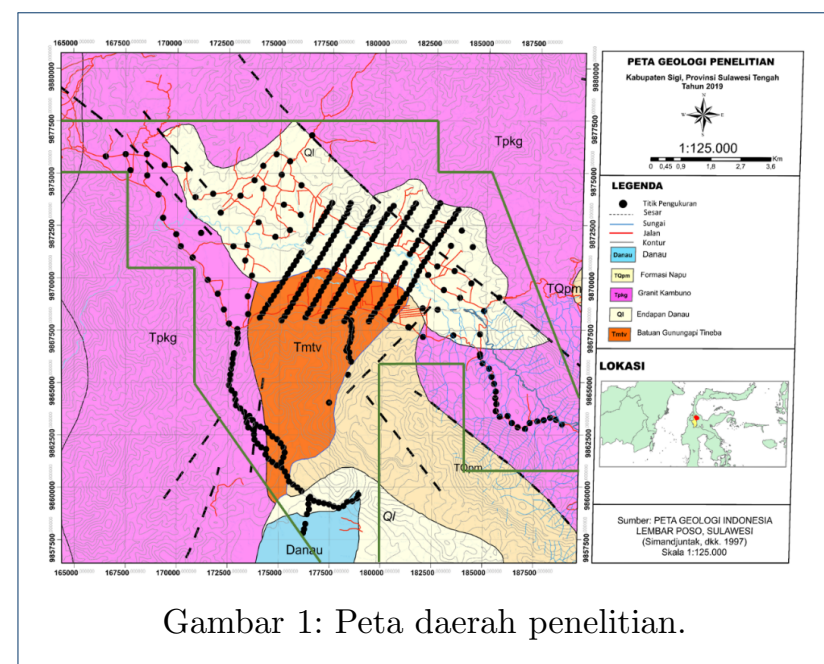

Data pada penelitian ini merupakan data sekunder yang diperoleh dari hasil pengukuran lapangan oleh Pusat Sumber Daya Mineral Batubara dan Panas Bumi (PSDMBP) Bandung pada tahun 2012 dan 2014. Data gravitasi hasil pengukuran lapangan oleh PSDMBP berupa data spasial, waktu pengukuran, dan data yang telah terkoreksi tinggi alat dan terkoreksi pasang surut, yang kemudian dilakukan pengolah dengan melakukan koreksi satuan mGal, tinggi alat, drift, pengikatan ke titik ikat di DG0 Bandung (977976,38). Selanjutnya data tersebut dilakukan beberapa koreksi untuk mengurangi beberapa efek yang dapat mempengaruhi nilai gravitasi di daerah tempat pengukuran, yaitu koreksi 
udara bebas, koreksi Bouguer sederhana, dan koreksi terrain untuk memperoleh anomali bouger lengkap (ABL). Nilai ABL merupakan anomali total di daerah pengukuran yang mengandung anomali lokal dan regional. Target dalam penelitian ini adalah anomali lokal, untuk mengetahui struktur bawah permukaan daerah panas bumi. Sehingga dilakukan pemisahan anomali lokal dan regional melalui metode kontinuasi ke atas, dengan mengurangkan anomali total dengan anomali regional. Sehingga diperoleh anomali lokal daerah penelitian. Anomali gravitasi lokal ini kemudian dianalisis dan dilakukan pemodelan tiga dimensi, untuk mendapatkan struktur bawah permukaan yang lebih nyata.

Pemodelan tiga dimensi dilakukan untuk interpretasi secara kualitatif dan kuantitatif struktur bawah permukaan. Dilakukan pemodelan ke belakang (inverse modelling) pada penelitian ini. Langkah pertama dalam melalukan pemodelan ini dengan membuat model awal menggunakan software Bloxer 1.6. Model awal tersebut dibuat dengan mempertimbangkan beberapa parameter berdasarkan tinjauan geologi dan penelitian sebelumnya, parameter tersebut diantaranya: densitas, kedalaman, dan kondisi geologi daerah penelitian. Pemodelan 3D struktur bawah permukaan berdasarkan anomali residual atau lokal dilakukan dengan menggunakan software Grablox 1.6 dan Bloxer 1.6. Model awal yang telah di buat kemudian dilakukan pemodelan ke belakang dengan bantuan software Grablox 1.6. Langkah-langkah dalam inversi yaitu: optimasi base, optimasi density, optimasi heights, dan Occam d serta Occam h. Sehingga diperoleh error yang cukup kecil yang menggambarkan tingkat kecocokan antara model dengan data pengukuran.

\section{HASIL DAN PEMBAHASAN}

Anomali Bouger sederhana hasil pengolahan sebelumnnya, kemudian dilakukan koreksi terrain untuk mendapatkan anomali Bouger lengkap (ABL) di topografi. Nilai ABL kemudian digunakan sebagai acuan untuk interpretasi data gravitasi secara kualitatif dan kuantitatif. Gambar 2 menunjukan anomali Bouger lengkap di topografi. Anomali Bouger lengkap daerah penelitian berada ada pada rentang 66 - 114 mGal. Anomali tinggi berada di bagian barat laut hampir utara daerah penelitian, dan anomali rendah berada di bagian timur laut hingga selatan daerah penelitian.

Pemisahan anomali lokal dan regional dilakukan pada Anomali total (ABL) dengan cara menggunakan metode kontinuasi ke atas. Anomali lokal atau residual diperoleh dengan mengurangkan anomali total dengan anomali regional. Gambar 3 menunjukan peta anomali

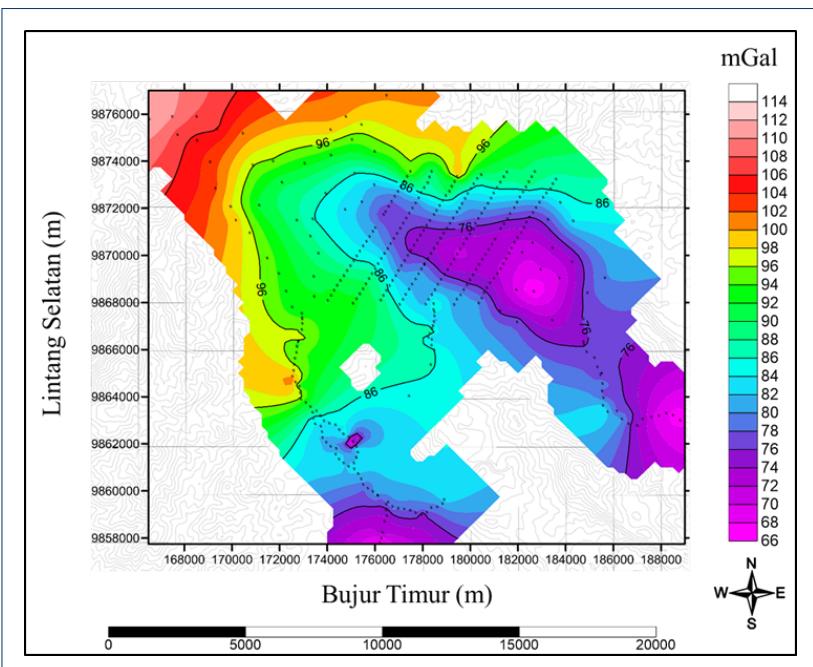

Gambar 2: Peta kontur anomali Bouger lengkap daerah panas bumi "K51S".

residual daerah penelitian. Anomali residual daerah penelitian berada pada rentang -10 - 13 mGal. Nilai anomali tinggi terlihat di bagian tengah tepatnya bagian arah barat daya daerah penelitian, sesuai dengan Gambar 3.

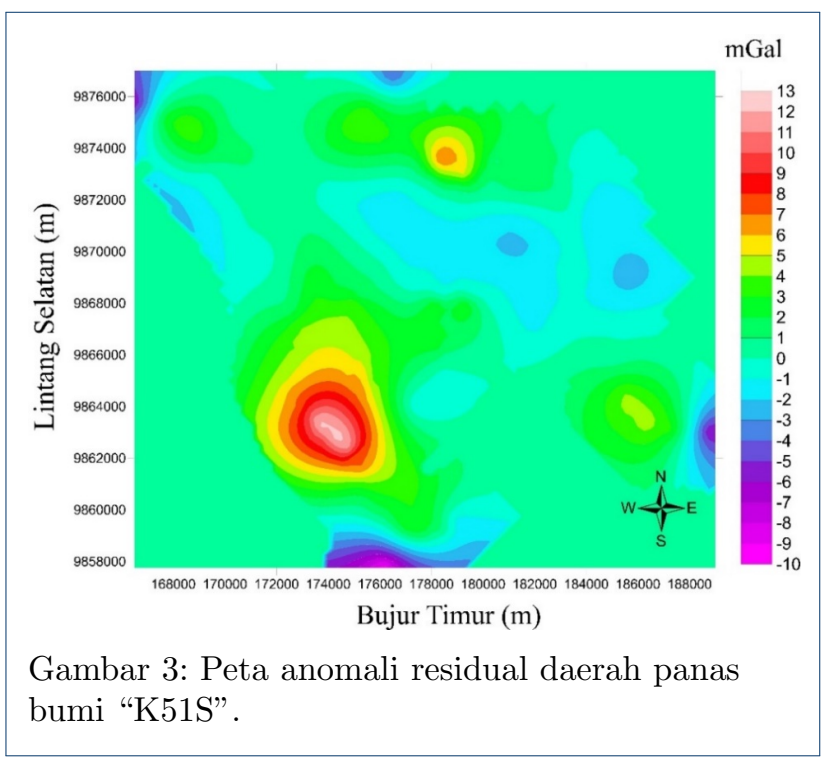

Pemodelan tiga dimensi dilakukan dengan membuat model awal, dengan tujuan memperoleh gambaran struktur bawah permukaan daerah penelitian secara lebih nyata. Model awal ini mempertimbangkan kondisi geologi daerah penelitian. Pada tahap pemodelan ke belakang, data anomali gravitasi yang digunakan adalah data anomali gravitasi residual sesuai target penelitian. Pemodelan dilakukan dengan bantuan software Grablox 1.6 dan Bloxer 1.6. Sesuai 
peta lembar geologi, daerah penelitian tersusun atas batuan alluvial, batupasir, granit, dan batuan vulkanik. Daerah penelitian memiliki batuan dengan densitas yang berada pada rentang $1,20-3,30 \mathrm{gr} / \mathrm{cm}^{3}$. Hasil pemodelan ke belakang menunjukan adanya kecocokan antara data pengukuran dan perhitungan dengan tingkat kesalahan (error) sebesar 5,56\%. Hal ini didukung dengan data RMS dan model RMS yang cukup kecil pada setiap tahap inversi. Gambar 4 menunjukan perbandingan model tiga dimensi antara model awal dan model akhir hasil inversi untuk setiap lapisan.

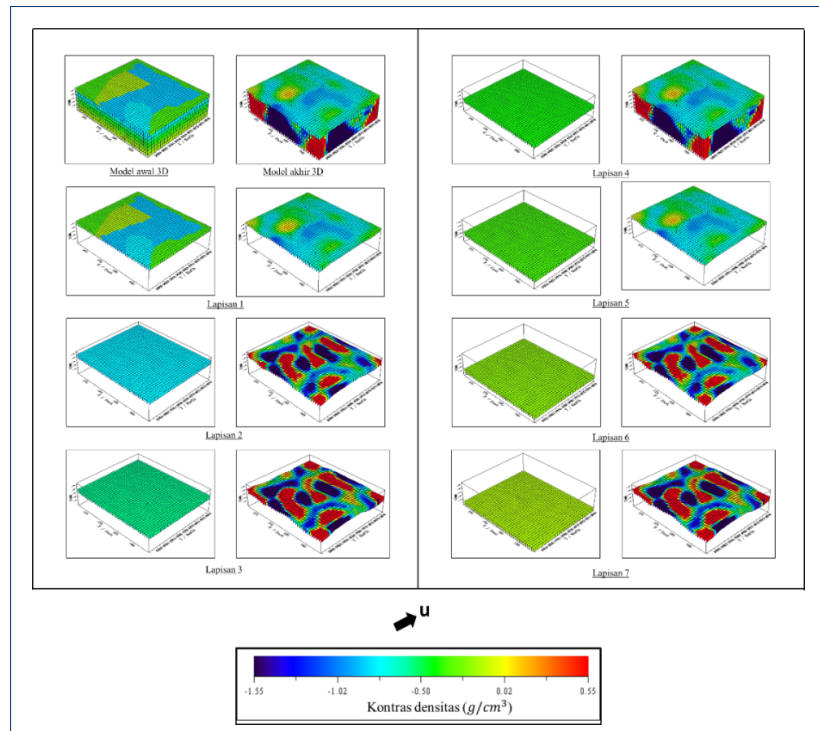

Gambar 4: Perbandingan model awal dan model akhir hasil inversi.

Hasil pemodelan tiga dimensi kemudian dilakukan interpretasi dengan menganalisis beberapa sayatan yang melewati jalur sesar dan manifestasi air panas daerah penelitian. Selain analisis model sayatan, interpretasi juga dilakukan secara kualitatif tinjauan geologi dan hasil pemodelan tiga dimensi.

Hasil interpretasi model sayatan menunjukan adanya batuan dengan densitas $1,20-3,30 \mathrm{~g} / \mathrm{cm}^{3}$. Batuan dengan densitas $1,20-2,34 \mathrm{~g} / \mathrm{cm}^{3}$ diinterpretasikan sebagai alluvial dan batupasir dengan densitas rendah (karena adanya tekanan yang cukup tinggi akibat adanya sesar), densitas 2,35 - 2,63 $\mathrm{gr} / \mathrm{cm}^{3}$ diinterpretasikan sebagai batupasir, densitas 2,64 - 3,30 $\mathrm{g} / \mathrm{cm}^{3}$ diinterpretasikan sebagai granit dan batuan vulkanik. Kenampakan anomali dengan densitas tinggi terdapat di sekitar mata air panas Koalarawa, Air hangat Towingkoloe dan Air panas Nokilalaki. Densitas tinggi tersebut diinterpretasikan sebagai granit. Kemudian anomali dengan densitas rendah terdapat disekitar air panas Kadidia dan endapan danau Lindu.

Hasil interpretasi secara kualitatif berdasarkan pemodelan tiga dimensi dan geologi daerah penelitian, menunjukan batuan alluvial terlihat di permukaan hingga kedalaman $\pm 0,2 \mathrm{~km}$. Batuan penudung (caprock) mulai terlihat pada kedalaman $0,8 \mathrm{~km}$ bersesuaian dengan batupasir. Batuan yang sama juga mulai terlihat pada kedalaman 1,3 km berupa batupasir dengan densitas lebih rendah. Batupasir dengan densitas rendah tersebut merupakan reservoir sebagi zona lemah tempat keluarnya fluida panas dari sumber panas bumi. Batuan dengan densitas tinggi berada pada kedalaman lebih dari $6 \mathrm{~km}$, yaitu batuan vulkanik dan granit. Batuan yang berperan sebagai heat source dari sistem panas bumi daerah penelitian diinterpretasikan sebagai granit. Model akhir tiga dimensi ditunjukan oleh Gambar 5. Hasil interpretsai model sayatan dan interpretasi kualitatif berdasarkan model tiga dimensi hasil inversi dan tinjauan geologi ditunjukan oleh Gambar 6.
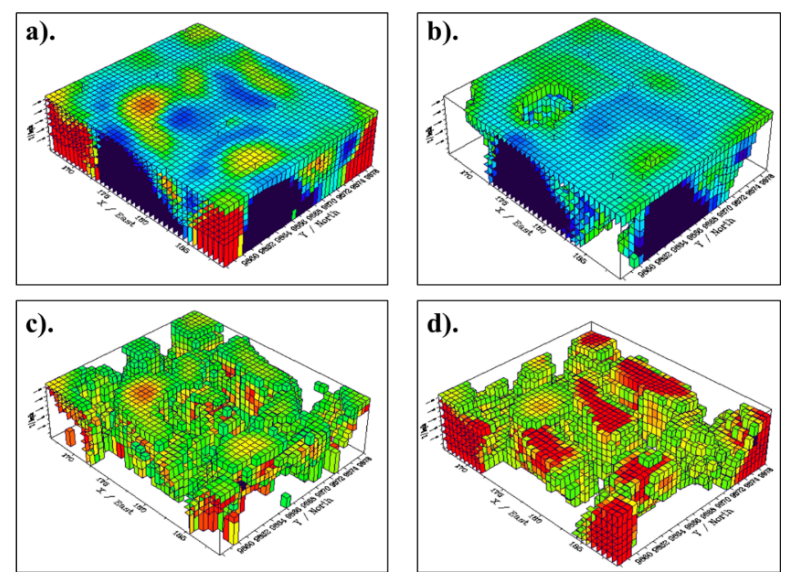

Gambar 5: Hasil pemodelan 3D data gravitasi anomali residual a). Model densitas bawah permukaan hasil inversi, b). Model densitas bawah permukaan $\left.\left(1,20-2,34 \mathrm{gr} / \mathrm{cm}^{3}\right), \mathrm{c}\right)$. Model densitas bawah permukaan $\left.\left(2,35-2,63 \mathrm{gr} / \mathrm{cm}^{3}\right), \mathrm{d}\right)$. Model densitas bawah permukaan $\left(2,64-3,30 \mathrm{gr} / \mathrm{cm}^{3}\right)$.

\section{KESIMPULAN}

Pola sebaran anomali residual dengan nilai tinggi pada rentang 5 - $13 \mathrm{mGal}$, bersesuaian dengan batuan vulkanik yang terdiri dari lava andesit, lava basalt, latit dan breksi berada di bagian tengah daerah penelitian. Anomali rendah dengan nilai $-10-4 \mathrm{mGal}$ tersebar merata di antara anomali tinggi daerah penelitian. Hasil pemodelan tiga dimensi sebaran denistas tinggi 2,64 - 3,30 


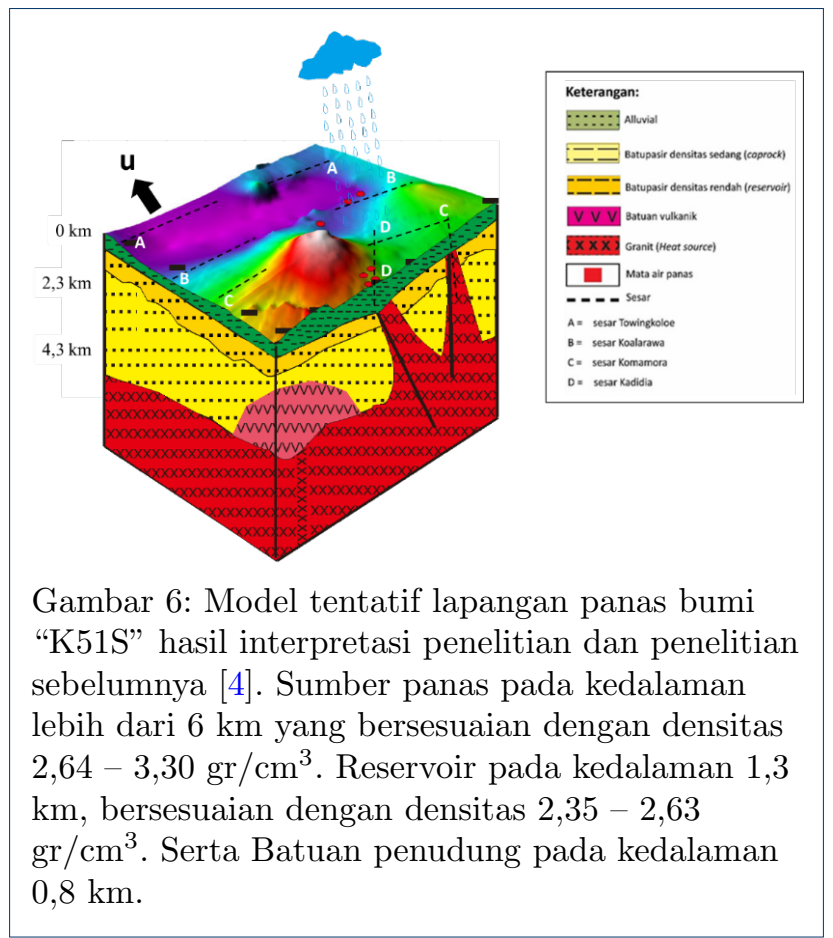

$\mathrm{gr} / \mathrm{cm}^{3}$ diinterpretasikan sebagai batuan vulkanik dan granit. Batuan densitas rendah $1,20-2,34 \mathrm{gr} / \mathrm{cm}^{3}$ diinterpretasikan sebagai batupasir densitas rendah dan alluvial, serta batuan dengan densitas sedang $2,35-2,63 \mathrm{gr} / \mathrm{cm}^{3}$ diinterpretasikan sebagai batupasir. Batuan yang diinterpretasikan sebagai sumber panas (heat source) dari sistem panas bumi daerah penelitian adalah granit, batuan reservoir adalah batupasir densitas rendah dan caprock adalah batupasir densitas sedang. Sesar pengontrol manifestasi panas bumi daerah penelitian adalah sesar Koalarawa dan sesar Towingkoloe. Hasil pemodelan tiga dimensi menunjukan kedalaman reservoir sistem panas bumi daerah penelitian adalah $1,3 \mathrm{~km}$, kedalaman heat source adalah lebih dari $6 \mathrm{~km}$ dan kedalaman caprock adalah $0,8 \mathrm{~km}$.

\section{PENULIS}

1 Anis Hoerunisa

Dari :

(1) Departemen Fisika, Fakultas Matematika dan Ilmu Pengetahuan, Universitas Gadjah Mada

2 Sismanto

Dari :

(1) Departemen Fisika, Fakultas Matematika dan Ilmu Pengetahuan, Universitas Gadjah Mada

Pustaka

1. Hall R, Blundell DJ. Tectonic evolution of southeast Asia. vol. 106. Geological Society Publishing House; 1996.

2. Jonan I, Mulyana R, Saefulhak Y. Potensi Panas Bumi di Indonesia. Jilid 1 ed.; 2017.

3. Zarkasyi A, Nurdin NM. Survei Magnetotelurik dan TDEM Daerah Panas Bumi Kadidia "K51S", Provinsi Sulawesi Tengah. Bandung: Pusat Sumber Daya Geologi; 2014.

4. Rahadinata T, Nurdin NM. Survei Terpadu AMT dan Gaya Berat daerah panas bumi Kadidia Selatan, Kabupaten Sigi, Provinsi Sulawesi Tengah. Bandung: Pusat Sumber Daya Geologi; 2014.

5. Fujimitsu Y, Nishijima J, Shimosako N, Ehara S, Ikeda K. Reservoir monitoring by repeat gravity measurements at the Takigami geothermal field, Central Kyushu, Japan. In: World Geothermal Congress, Beppu-Marioka, Japan, by International Geothermal Association; 2000. . 